\title{
Perencanaan Strategi SI/TI menggunakan metode Ward and Peppard (Studi Kasus: Dinas Pendidikan dan Kebudayaan, Kabupaten Bengkayang)
}

\author{
Oktaviana Ayu ${ }^{1}$, Agustinus Fritz Wijaya ${ }^{2}$ \\ Program Studi Sistem Informasi \\ Fakultas Teknologi Sistem Informasi, Universitas Kristen Satya Wacana \\ Email: ${ }^{1682017410 @ s t u d e n t . u k s w . e d u},{ }^{2}$ agustinus.wijaya@uksw.edu
}

\begin{abstract}
Abstrak
Sistem Informasi merupakan sebuah keterkaitan antara manusia, prosedur, serta penggunaan teknologi yang digunakan untuk mengumpulkan, mengolah, menyimpan, menyebarkan dan menyajikan informasi yang digunakan oleh suatu proses bisnis dalam organisasi. Tujuan penulisan adalah peneliti dapat menghasilkan perencanaan strategis sistem informasi di Dinas Pendidiikan dan Kebudayaan Kabupaten Bengkayang. Metode yang digunakan adalah metode kualitatif deskriptif. Perencanaan strategis SI / TI Disdikbud Kab. Bengkayang dilakukan dengan metode Ward and Peppard, tahapannya antara lain menganalisis lingkungan bisnis internal dan eksternal organisasi, menganalisis SI / TI internal dan eksternal organisasi, dilanjutkan dengan proses penentuan strategi dan merancang portofolio. Dinas Pendidikan dan Kebudayaan Kab. Bengkayang saat ini penerapan SI/TI nya belum maksimal dan masih terdapat beberapa kekurangan dalam pemanfaatan SI / TI pada Dinas Pendidikan dan Kebudayaan yang perlu dikembangkan dan diimplementasikan untuk membantu kemajuan. Perlu merancang strategi dalam proses bisnis untuk bersaing atau mendapatkan peluang dan memperbaiki kondisi. Dengan strategi yang baik dan matang, rencana siap menghadapi persaingan dan tantangan.

Kata kunci: Perencanaan Strategi Sistem Informasi, Ward and Peppard, Value Chain, Mc Farlan Strategic Grid, Aplikasi Portofolio
\end{abstract}

\section{PENDAHULUAN}

Di era teknologi informasi yang pesat saat ini, kegiatan bisnis suatu organisasi tidak terlepas dari peran Sistem Informasi (SI) dan Teknologi Informasi (TI). Dengan adanya SI/TI pada suatu organisasi akan lebih efisien dan efektif dalam pelayanannya. Perencanaan Strategi pada sebuah pemerintahan merupakan bagain terpenting untuk mencapai suatu tujuan pemerintahan dan akan menjadi pedoman dalam penyusunan strategi. Pengembangan sistem informasi pada pemerintahan dan di dukung oleh teknologi 
Vol. 1, No. 1, January 2020 e-ISSN: xxxx-xxxx

https://journal-computing.org/index.php/journal-cisa/index

informasi menjadi salah satu strategi dalam meningkatan kinerja dan daya saing. Teknologi dan sistem informasi telah menjadi kebutuhan suatu organisasidalam menjalankan bisnis dan layanan. Pemerintahan juga menggunakan teknologi dan system informasi untuk melaksanakan kegiatan dan pelayanan. Teknologi dan system informasi telah banyak dilakukan pemerintah, namun masih belum optimal. Salah satu penyebabnya adalah penerapan SI/TI yang kurang baik. Dengan cara penataan ulang organisasi, dengan melibatkan manfaat dari Sistem Informasi dan Teknologi Informasi (SI/TI) akan meningkatkan inovasi strategi yang paling tepat agar memperoleh keunggulan kompetitif.

Semakin tinggi tingkat permintaan SI / TI dalam kehidupannya, maka semakin banyak pula masyarakat yang masih belum mengetahui dan memahami sistem teknisnya. Di era revolusi industri 4.0, perusahaan harus menerapkan teknologi informasi untuk mencapai kelangsungan bisnis dalam persaingan yang semakin ketat. Selain perusahaan, instansi pemerintah juga tidak terlepas dari penerapan teknologi informasi secara efektif dan efisien dalam memberikan pelayanan kepada masyarakat. Proses penerapan teknologi informasi dan komunikasi sebagai alat bantu sistem pemerintahan dalam memberikan pelayanan sering disebut dengan e-government atau sistem pemerintahan berbasis elektronik (SPBE).

Pemerintah Dinas Pendidikan dan Kebudayaan memiliki tugas pokok dan fungsi dalam penyelenggaraan dan pengelolaan pendidikan dan kebudayaan di daerah. Pendidikan merupakan salah satu pelayanan dasar yang perlu ditangani oleh pemerintah secara profesional. Ada banyak pihak yang berkepentingan dalam Pendidikan dan kebudayaan. Dinas pendididkan dan kebudayaan kabupaten Bengkayang merupakan unsur pelaksana daerah yang dipimpin oleh Kepala Dinas di bawah naungan Bupati melalui sekretaris daerah. Dinas pendidikan bertanggung jawab atas pendidikan dan pemerintahan. Dinas Pendidikan dan Kebudayaan Kabupaten Bengkayang telah membuat rencana strategi tahun 2016-2021. Dalam dokumen rencana strategi menjelaskan bahwa 
Vol. 1, No. 1, January 2020 e-ISSN: xxxx-xxxx

https://journal-computing.org/index.php/journal-cisa/index

pada Dinas Pendidikan belum semua bagian menggunakan SI/TI. Oleh karena itu pada penelitian ini peliti akan menganalisis lebih lanjut pada Dinas Pendidikan Kabupaten Bengkayang. Dinas Kabupaten yang telah menggunakan SI/TI hanya bagian keuangan saja. Oleh karena itu, peneliti akan menganalisis lebih lanjut mengenai penggunaan SI/TI kepada Dinas Pendidikan dan Kebudayaan Kabupaten Bengkayang.

Untuk membantu proses analisis sistem informasi dalam sebuah organisasi pemerintahan, maka akan digunakan Perencanaan Strategis Sistem Informasi (PSSI) untuk mengetahui secara jelas strategi-strategi dan critical success factors. Sehingga nantinya dihasilkan portfolio aplikasi yang berisi sejumlah alternatif teknologi informasi sesuai dengan keadaan organisasi pemerintah. Perkembangan SI/TI saat ini sangat pesat, sehingga telah dianggap sebagai sumber daya yang sangat penting bagi organisasi (baik organisasi pemerintah maupun organisasi swasta), (Hammer \& Champy, 1993), yang tidak hanya berperan sebagai suatu dukungan semata, namun juga telah berperan sebagai key operational, high potential, peran strategis, dan dapat dimanfaatkan untuk mendukung efektivitas, efisiensi, dan produktivitas dalam organisasi.

Hal yang menjadi permasalahan dalam penelitian ini adalah bagaimana merancang suatu IT strategic planning yang sesuai dengan kebutuhan Dinas Pendidikan sehingga dapat mendukung Dinas Pendidikan dan Kebudayaan dalam menjalankan kinerja proses bisnisnya. Dalam penelitian ini, metode Ward and Peppard menggunakan beberapa teknik analisis, SWOT, dan PEST untuk menganalisis lingkungan internal dan eksternal bisnis. Untuk menganalisis lingkungan internal dan eksternal SI maupun TI menggunakan portofolio aplikasi saat ini, dan McFarlan Strategic digunakan untuk pemetaan portofolio aplikasi. Penelitian ini diharapkan dapat menghasilkan perencanaan strategis sistem informasi di Dinas Pendidiikan dan Kebudayaan Kabupaten Bengkayang. 
Vol. 1, No. 1, January 2020 e-ISSN: xxxx-xxxx

https://journal-computing.org/index.php/journal-cisa/index

\section{TINJAUAN PUSTAKA}

Sistem Informasi merupakan sebuah keterkaitan antara manusia, prosedur, serta penggunaan teknologi yang digunakan untuk mengumpulkan, mengolah, menyimpan, menyebarkan dan menyajikan informasi yang digunakan oleh suatu proses bisnis dalam organisasi (Grant dkk., 2010). Sistem Informasi adalah sebuah perangkat dengan menggunakan teknologi untuk mengumpulkan, memproses, menyimpan, menyebarkan, dan menyajikan informasi yang dibutuhkan oleh suatu organisasi. Teknologi Informasi adalah pemanfaatan teknologi terutama hardware, software, and telecommunication networks baik tangible dan intangible sebagai fasilitas untuk acquisition, processing, stroring, delivery and sharing of information. TI berguna untuk menyediakan fasilitas dalam berjalannya seluruh proses dan fungsi sistem informasi secara berkelanjutan (Anggraeni, 2017).

Sistem informasi adalah sebagai satuan komponen yang saling berhubungan dalam mengumpulkan (atau mendapatkan kembali), memproses, menyimpan, dan mendistribusikan informasi untuk mendukung pengambilan keputusan dan kendali dalam suatu organisasi. Sistem informasi tidak dapat diabaikan oleh para manajer sebab system informasi tesebut memainkan aturan penting dalam organisasi kontemperor (Loudon dan Laudon, 2005, p.9-p.10). dan Teknologi informasi adalah menunujukan pada spesifikasi mengenai teknologi, khususnya hardware, software dan jaringan telekomuikasi yang memfasilitasi dan mendukung proses pengumpulan, pengolahan, penyimpanan, penyebaran dan pertukaran informasi (Ward dan Peppard (2002, p.3)

Perencanaan strategis system informasi adalah suatu proses untuk menyusun perencanaan untuk penggunaan dan implementasi sistem dan teknologi secara komprehensif pada suatu organisasi / enterprise yang sejalan (aligned) dengan strategi bisnis organisasi/enterprise untuk mendukung pencapaian tujuan (goals) organisasi secara efektif dan efisien (Lederer \& Gardiner, 1992). Truitt (2002) menguraikan berbagai manfaat perencanaan, antara 
Vol. 1, No. 1, January 2020 e-ISSN: xxxx-xxxx

https://journal-computing.org/index.php/journal-cisa/index

lain untuk menyadarkan organisasi agar memahami dan menyadari tentang masa depan, mendisiplinkan organisasi, menekankan pilihan pilihan keputusan, menyadarkan para pemimpin bahwa mereka harus mengelola lembaga dan membuat para manajer berpikir. Terdapat perbedaan pemahaman rencana strategis menurut para ahli. Dalam hal ini perlu pembedaan tentang apa yang disebut rencana Strategis (Strategic plan) dengan rencana Usaha (Business Plan). "Perencanaan strategis adalah proses analisis kekuatankekuatan internal perusahaan dan kekuatan-kekuatan eksternal (peluang dan ancaman) suatu pasar, perumusan dan evaluasi strategi-strategi untuk mengatasi ancaman eksternal dan merebut peluang yang ada" (Rangkuti $(2003$, h.6)).

\section{METODELOGI PENELIAN}

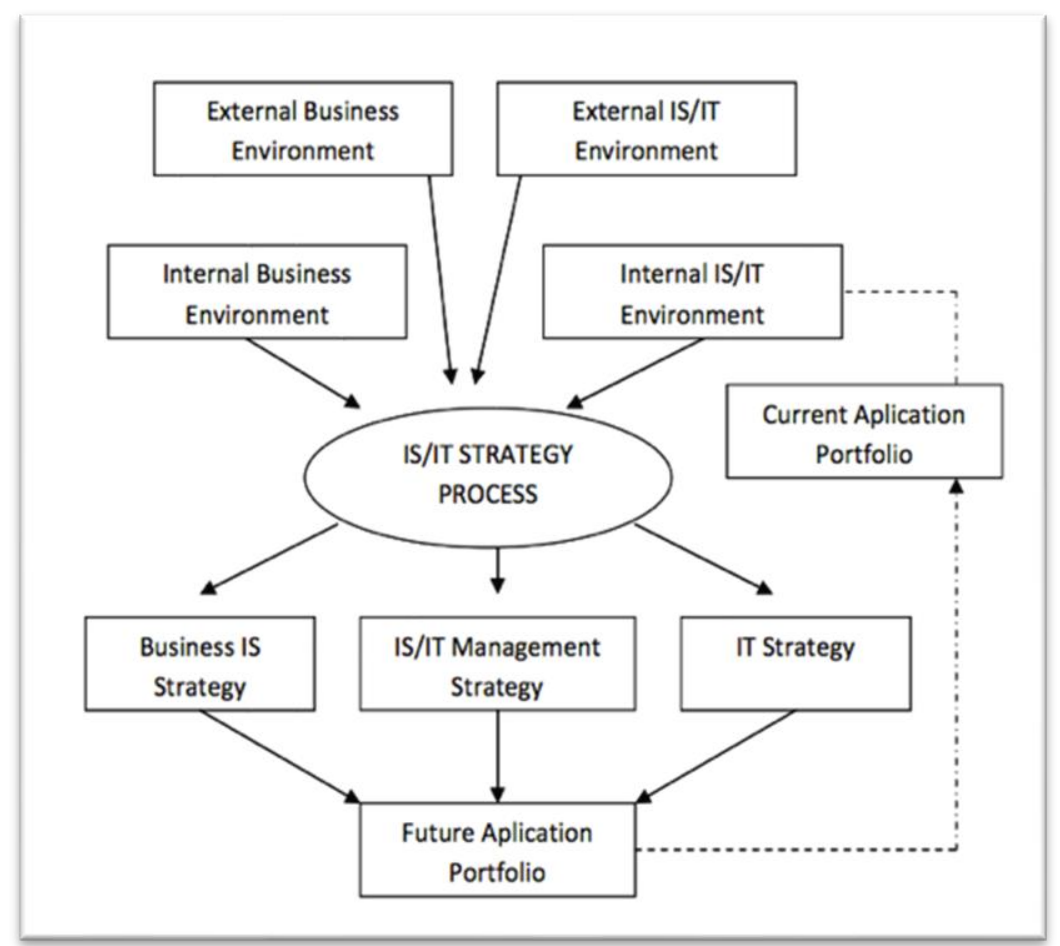

Strategi SI/TI menggunakan metodelogi Ward and Peppard [Ward \& Peppard 2002] 
Vol. 1, No. 1, January 2020 e-ISSN: xxxx-xxxx

https://journal-computing.org/index.php/journal-cisa/index

Berdasarkan permasalahan yang ada pada Dinas Pendidikan dan Kebudayaan Kabupaten Bengkayang, peneliti menggunakan metode kualitatif deskriptif dan responden Lidiana Koni, SP selaku Kepala subbagian umum dan kepegawaian. Sehingga dalam pengambilan data dilakukan secara wawancara dan observasi langsung di Dinas Pendidikan dan Kebudayaan Kabupaten Bengkayang. Dengan metode ini penulis mendeskripsikan dan menjabarkan secara jelas langkah-langkah yang dibutuhkan untuk melakukan perencanaan stratregi. Penelitian ini menggunakan beberapa metode yang meliputi analisis SWOT, analisis value chain, analisis PEST, dan analisis McFarlan Strategic Grid (Ward and Peppard, 2002).

Perlu kita pahami dari kerangka di atas bahwa dalam menentukan perencanaan strategis harus mengikuti prosedur yang ada. Untuk mendapatkan efek yang maksimal, kita harus menggunakan tools. Oleh karena itu, dalam penelitian ini penulis akan mendeskripsikan prosedur yang ada pada kerangka diatas satu persatu. Metodologi Ward and Peppard dapat di jelaskan melalui tahapan-tahapan sebagai berikut:

1. Analisis Lingkungan Bisnis Internal, mengidentifikasi faktor lingkungan bisnis, sejauh mana Dinas Pendidikan dan Kebudayaan telah mencapai tujuannya, dan apa saja yang perlu ditingkatkan dan dikembangkan untuk meningkatkan keuntungan kompetitif dan bisa menjadi nilai tambah.

2. Analisis Lingkungan Bisnis Eksternal, mencakup politik, ekonomi, sosial dan teknologi

3. Analisis Lingkungan SI/TI Internal, Meliputi kondisi SI / TI Dinas Pendidikan dan Kebudayaan Kabupaten Bengkayang dengan melihat kondisi bisnis saat ini

4. Analisis Lingkungan SI/TI Eksternal, mencakup tren teknologi dan pemanfaatannya

\section{HASIL DAN PEMBAHASAN}

Visi dan misi Dinas Pendidikan dan Kebudayaan Kabupaten Bengkayang adalah harapan dan tantangan dalam mewujudkan 
Vol. 1, No. 1, January 2020 e-ISSN: xxxx-xxxx

https://journal-computing.org/index.php/journal-cisa/index

harapan tersebut. Pencapaian visi dan misi tersebut adalah untuk memenuhi tugas, fungsi, dan wewenang Dinas Pendidikan dan Kebudayaan Kabupaten Bengkayang dengan memperhatikan nilai, karakteristik, dan prinsip yang telah ditetapkan, melalui pelaksanaan tujuan dan rencana strategis.

Visi: "Terbentuknya insan yang cerdas dan berkarakter serta berdaya saing"

Misi:

1. Mewujudkan tenaga pendidik dsn kependidikan pada semua jenjang serta pelaku kebudayaan yang berkualitas.

2. Meningkatkan akses pelayanan Pendidikan yang meluas, merata dan berkeadilan.

3. Meningkatkan pembelajaran yang bermutu.

4. Mewujudkan pelestarian seni dan budaya serta peningkatan prestasi olahraga pelajar pada semua jenjang Pendidikan.

5. Penguatan tata kelola serta peningkatan efektivitas birokrasi yang transparan dan akuntabel

\section{Analisis Lingkungan Bisnis Internal dan Eksternal}

- Analisis SWOT

Menurut Tozer (1996), Analisis SWOT merupakan proses untuk menidentifikasi factor internal (strength and weakness) dan faktor eksternal (opportunity and threat) dari organisasi secara sistematis untuk merumuskan strategi organisasi.

Analisis SWOT merupakan proses menganalisis kekuatan (strength), kelemahan (weakness), peluang (opportunity), dan ancaman (threart) untuk menilai kondisi lingkungan internal pada perusahaan/organisasi. Berikut hasil analisis SWOT pada Dinas Pendididkan dan Kebudayaan Kabupaten Bengkayang:

\section{SWOT ANALYSIS}

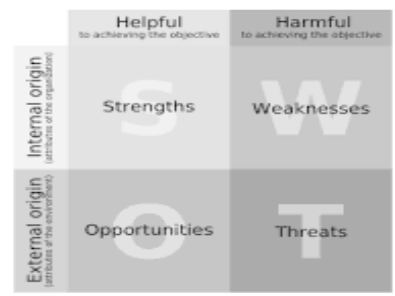


Vol. 1, No. 1, January 2020 e-ISSN: xxxx-Xxxx

https://journal-computing.org/index.php/journal-cisa/index

a. Kekuatan (Strengths): Dapat mengontrol perkembangan dari sistem pemerintahan.

b. Kelemahan (Weakness): Perkembangan Dinas Pendidikan yang masih lambat, belum memiliki website khusus Dinas Pendidikan yang dapat diakses oleh masyarakat, masih kurangnya karyawan terutama pada bidang IT, sistem proses kerja yang masih kurang cepat.

c. Peluang (Opportunities): Lokasi sarana pendidikan yang semakin jauh dengan permukiman, khususnya permukiman baru, Pendidikan berbasis teknologi informasi dan pendidikan berbasis kearifan lokal yang berwawasan global masih kurang, memiliki peluang untuk menciptakan sebuah teknologi baru.

d. Ancaman (Threats): Jaringan pada daerah yang belum maksimal/memadai.

- Analisis Value Chain

Analisis Value Chain dilakukan untuk menggambarkan aktifitas utama dan aktifitas pendukung pada suatu perusahaan/organisasi untuk meraih keunggulan kompetitif. Keunggulan kompetitif dapat di realisasikan dalam hal mendapatkan keunggulan strategis, taktis maupun operasional. Berikut hasil value chain di Dinas Pendidikan dan Kebudayaan Kabupaten Bengkayang.

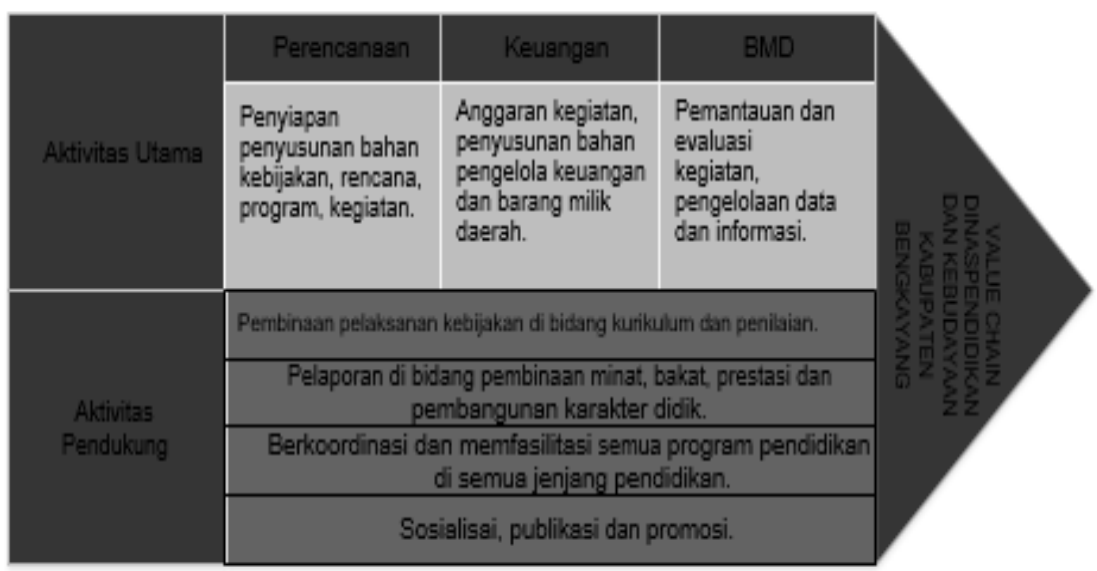


Vol. 1, No. 1, January 2020 e-ISSN: xxxx-xxxx

https://journal-computing.org/index.php/journal-cisa/index

Aktifitas utama dan aktifitas pendukung pada Dinas Pendidikan dan Kebudayaan Kabupaten Bengkayang di gambarkan melalui diagram value chain, yang meliputi:

1. Aktifitas utama:

a. Perencanaan: penyiapan penyususnan bahan kebijakan, rencana, program, kegiatan.

b. Keuangan: anggaran kegiatan, penyusunan bahan pengelolaan keuangan dan barang milik daerah.

c. BMD: pemantauan dan evaluasi kegiatan, pengelolaan data dan informasi.

2. Aktifitas pendukung:

a. Pembinaan pelaksanaan kebijakan di bidang kurikulum dan penilaian.

b. Pelaporan di bidang pembinaan minat, bakat, prestasi dan pembagunan karakter didik.

c. Berkoordinasi dan memfasilitasi semua program Pendidikan di semua jenjang pendidikan

d. Sosialisai, publikasi, dan promosi.

- Analias PEST

Analisis PEST adalah perencanaan strategi yang dilakukan untuk mengetahui perkembangan bisnis pada perusahaan atau organisasi dan digunakan juga untuk mengevaluasi dampak dari factor-faktor: Politik, Ekonomi, Sosial, dan Teknologi.

a. POLITIK

Secara politik Dinas Pendidikan mengikuti regulasi pemerintah terhadap ketenagakerjaan yang terdapat pada Dinas Pendidikan dan Kebudayaan Kabupaten Bengkayang

b. EKONOMI

Secara ekonomi Dinas mengikuti perkembangan ekonomi di kabupaten Bengkayang. Selain mengikuti perkembangan ekonomi, di Dinas Pendidikan iuga memiliki pegawai CPNS dan juga Honorer

c. SOSIAL

Secara sosial Dinas Pendidikan bersosialisasi dengan dinas lain yang berkepentingan dan komunikasi dengan masyarakat

d. TEKNOLOGI 
Vol. 1, No. 1, January 2020 e-ISSN: xxxx-xxxx

https://journal-computing.org/index.php/journal-cisa/index

Perkembangan teknologi yang semakin pesat saat ini bisa menjadi pemicu keberhasilan bisnis pada perusahaan maupun organisasi untuk mencapai suatu tujuan.

\section{Analisa Lingkungan SI/TI pada Dinas Pendidikan dan Kebudayaan}

Dalam sebuah perusahaan / organisasi, teknologi sangat penting untuk mencapai suatu keberhasilan. Di Dinas Pendidikan dan Kebudayaan, aplikasi teknologi masih minim. Sehingga menghambat kemajuan teknologi.

\section{- Rekomendasi Sistem Informasi}

Information Tecnology strategic planning yang diusulkan terdiri dari beberapa rekomendasi yang terdiri dari beberapa strategi yaitu strategi bisnis SI, strategi manajemen SI/TI dan strategi TI yang merekomendasikan strategi. Strategi yang diperlukan oleh Dinas Pendidikan dan Kebudayaan Kabupaten Bengkayang untuk meningkatkan keunggulan kompetitif berdasarkan analisa yang telah dilakukan sehingga dapat disusun portofolio aplikasi untuk tahun yang akan menadatang untuk Dinas Pendidikan dan Kebudayaan Kabupaten Bangkayang.

\begin{tabular}{|c|c|l|}
\hline $\begin{array}{c}\text { Nama Sistem } \\
\text { Informasi }\end{array}$ & Pengguna & \multicolumn{1}{|c|}{ Fungsi } \\
\hline $\begin{array}{c}\text { SI Manajemen } \\
\text { Keuangan }\end{array}$ & $\begin{array}{c}\text { Bagian } \\
\text { Keuangan }\end{array}$ & $\begin{array}{l}\text { Mengatur manajemen } \\
\text { keuangan Dinas Pendidikan } \\
\text { dan Kebudayaan }\end{array}$ \\
\hline SI Manajemen SDM & $\begin{array}{l}\text { Karyawan, } \\
\text { Customer }\end{array}$ & $\begin{array}{l}\text { Mengatur menajemen } \\
\text { sumber daya manusia }\end{array}$ \\
\hline SI Manajemen Aset & Karyawan & $\begin{array}{l}\text { Sebagai sarana pengolahan } \\
\text { Asset }\end{array}$ \\
\hline Web Promosi & Karyawan & Sebagai sarana promosi \\
\hline
\end{tabular}

\section{- Portofolio Aplikasi}

MC Farlan Strategic Grid memberikan kemudahan untuk melihat kondisi dan strategi SI / TI saat ini serta kebutuhan dimasa mendatang pada suatu perusahaan atau organisasi. Dari hasil pemetaan aplikasi MC Farlan dapat diketahui bahwa aplikasi 
Vol. 1, No. 1, January 2020 e-ISSN: xxxx-Xxxx

https://journal-computing.org/index.php/journal-cisa/index

memiliki empat kuadran sesuai dengan kategori evaluasi dampak bisnis aplikasi, meliputi strategic, high potential, key operational and support. Dari hasil pemetaan tersebut dapat diperoleh gambaran kontribusi SI / TI terhadap bisnis. Hasil tersebut dapat digunakan sebagai masukan untuk kegiatan perumusan strategi information system dan kemungkinan pengembangannya ke depan.

\begin{tabular}{l|l}
\hline STRATEGIC & HIGH POTENTIAL \\
\hline Web Promosi & SI Manajemen Keuangan
\end{tabular}

\begin{tabular}{l|l}
\hline SUPPORT & KEY OPERATIONAL \\
\hline Ms. Word & SI Manajemen SDM \\
Ms. Exel & SI Manajemen Aset
\end{tabular}

\section{- Analisa Kesenjangan Aplikasi}

Rencana implementasi sistem informasi telah disesuaikan dengan portofolio aplikasi yang dipetakan oleh MC Farlan. Rencana strategis tersebut dapat membantu Dinas Pendidikan menggunakan daftar prioritas untuk mengembangkan sistem informasi.

\begin{tabular}{lccc}
\hline $\begin{array}{l}\text { Usulan Sistem } \\
\text { Informasi }\end{array}$ & Upgrade & Delete & Planning \\
\hline SI Manajemen & $\checkmark$ & - & $\checkmark$ \\
Keuangan & & & \\
SI Manajemen Aset & - & - & $\checkmark$ \\
Web Promosi & - & - & $\checkmark$ \\
SI Manajemen SDM & - & - & $\checkmark$
\end{tabular}

\section{KESIMPULAN}

Berdasarkan hasil analisis dan pembahasan penelitian ini, dapat disimpulkan bahwa Dinas Pendidikan dan Kebudayaan Kab. Bengkayang saat ini penerapan SI/TI nya belum maksimal dan masih terdapat beberapa kekurangan dalam pemanfaatan SI / TI 
Vol. 1, No. 1, January 2020 e-ISSN: xxxx-xxxx

https://journal-computing.org/index.php/journal-cisa/index

pada Dinas Pendidikan dan Kebudayaan yang perlu dikembangkan dan diimplementasikan untuk membantu kemajuan. Perlu merancang strategi dalam proses bisnis untuk bersaing atau mendapatkan peluang dan memperbaiki kondisi. Dengan strategi yang baik dan matang, rencana siap menghadapi persaingan dan tantangan. Perencanaan strategis SI / TI Disdikbud Kab. Bengkayang dilakukan dengan metode Ward and Peppard, tahapannya antara lain menganalisis lingkungan bisnis internal dan eksternal organisasi, menganalisis SI / TI internal dan eksternal organisasi, dilanjutkan dengan proses penentuan strategi dan merancang portofolio investasi masa depan untuk membantu perusahaan berkembanganAlur kerja organisasi.

Saran untuk penelitian selanjutnya diharapkan dapat dipelajari dengan menggunakan metode penelitian yang lebih luas lagi. Sehingga bisa mendapatkan hasil yang lebih maksimal. Peru pembentukan tim ahli TI / manajemen pengembangan SI / TI departemen TI agar dapat membantu mengevaluasi dan meninjau hasil yang diperoleh dari proses penyusunan dan penerapan strategi SI / TI.

\section{DAFTAR PUSTAKA}

[1] Y. Firmansyah and D. Purwaningtias, "Analisa Metodologi Ward \& Peppard Dalam Penentuan Perencanaan Strategis SI/TI," Cybernetics, vol. 1, no. 02, p. 70, 2017.

[2] K. Imtihan, "Perencanaan Strategi Sistem Informasi Pendidikan Pada Sekolah Tinggi Manajemen Informatika dan Komputer ( STMIK ) Lombok," Bianglala Inform., vol. 3, no. 2, pp. 73-78, 2015.

[3] Widyaningsih, P. 2012. Perencanaan Strategis Sistem Informasi Pada Institusi Pendidikan Tinggi Menggunakan Analisis Critical Success Factors (Studi Kasus : STMIK Duta Bangsa Surakarta), Tesis. Pascasarjana Universitas Diponegoro. Semarang.

[4] Setyono, Y. A., Wijaya, A. F, Sitokdana, M. N. N. 2019. Perencanaan Strategis Sistem Informasi Menggunakan Ward 
Vol. 1, No. 1, January 2020 e-ISSN: xxxx-xxxx

https://journal-computing.org/index.php/journal-cisa/index

and Peppard (Studi kasus: Gereja Kristen Jawa Plengkung). Universitas Kristen Satya Wacana..

[5] Arifani, I.N., dan Abdi D. 2016. Perencanaan Strategis Sistem Informasi Dan Teknologi Informasi SI/TI Pendidik Dan Tenaga Kependidikan (Studi Kasus: Pada Disdikbudpora Metro). Jurnal TIM Darmajaya Vol. 02 No. 01.

[6] Damara, V. D. R., dan Wijaya A. F. 2020. Perencanaan Strategis SI/TI Pada Document Management Menggunakan Ward And Peppard (Studi Kasus : PT. Visionet Data International). Jurnal Bina Komputer JBK, Vol. 2, No. 1.

[7] Adwiya, R. 2015. Perancanaan Strategis SI/TI Menggunakan Four Stage Model Pada Dinas Pendidikan Kabupaten Kubu Raya Kalimantan Barat. Jurnal Khatulistiwa Informatika, VOL. 3, NO. 2.

[8] Sylvia, C, Angela,. (2012). Perencanaan strategis Sistem dan Teknologi Informasi pada STMIK-STIE Mikroskil menggunakan metode Ward and Peppard. STMIK : Medan.

[9] Kusuma, C.R \& Ghozali, K,. (2019). Perencanaan Strategi Sistem Informasi Dinas Pendidikan Kabupaten Lamongan Berdasarkan Perpres No.95 Tahun 2018. Jurnal Teknik ITS Vol.8, No.2, ISSN: 2337-3539 (2301-9271)

[10] Adwiya, R,. (2015). Perencanaan Strategi SI/TI Menggunakan Four Stage Model pada Dinas Pendidikan Kabupaten Kubu Raya Kalimantan Barat. Jurnal Khatulistiwa Informatika, Vol. 3, No. 2. 